\title{
LA COLONISATION VALAQUE SUR LES VERSANTS NORD DES CARPATES PENDANT LE PETIT ÂGE GLACIAIRE (AUX XVE ET XVIE SIÈCLES )
}

\author{
GRZEGORZ JAWOR
}

\begin{abstract}
The Wallachian settlement on the northern slopes of the Carpathians in the Little Ice Age (15th and 16 th century).

A significant deterioration of climate took place in the Carpathians in the period from the 15 th to the 19th century. It was a fragment of a global phenomenon referred to by various representatives of geoscience as the Little Ice Age (LIA). Arguments presented in the article were preceded by a preliminary assumption that these events had a particular impact on the living conditions of populations who inhabited the areas situated in the sub-mountain and mountain zones in the 15th and 16th century. Located in this area were the upper levels of various cultivated plants' ranges, which were particularly crucial for the cultivation of winter cereal crops. Even minor fluctuations of multi-annual average temperatures could significantly increase or decrease them. The results contained in this work were formed on the basis of information from the sources, which are primarily of a fiscal nature and which so far have been underrated by historians of the climate. The analysis of changes taking place in individual settlements was conducted on the other hand by using the methodology applied by historians of human settlement. The outcome of the studies presented below offers a general conclusion on the existence of a widespread phenomenon in the discussed period of an increase in the Carpathian areas of the elements from a model of the economic functioning of the village life which was based on stockbreeding. This happened at the expense of restricting or sometimes even eliminating agricultural activities. It was the main reason for which individual landowners fostered or initiated colonization based on the Wallachian law or, at least, on its elements. For this reason, the 16th century in particular became a period of a sudden development of this settlement trend in the Carpathian regions. This had serious consequences not only for the economy. The study draws attention to the fact that the introduction of these changes could take place due to the migration of ethnically foreign people who were acquainted with the secrets of specialised stockbreeding, which was unavailable to classical farmers. Amongst the newcomers were also ethnic Vlachs. One of the consequences of these migrations was also a considerable increase in the scope of Orthodoxy at the expense of Catholicism in Lesser Poland.
\end{abstract}

STRESZCZENIE. Osadnictwo wołoskie na pótnocnych stokach Karpatów podczas małej epoki lodowej (XVi XVI w.).

W okresie od XV do XIX wieku w Karpatach miało miejsce znaczące pogorszenie klimatu. Jest to fragment zjawiska globalnego, przez przedstawicieli różnych nauk o ziemi zwane Małą Epoką Lodową (MEL). Rozważaniom zawartym w artykule towarzyszyło wstępne założenie, że te wydarzenia miały szczególny wpływ na warunki egzystencji społeczności zasiedlających na przestrzeni XV i XVI stulecia obszary położone w strefie podgórskiej i górskiej. Na tym obszarze znajdują się górne piętra zasięgu różnych roślin uprawnych, zwłaszcza kluczowych dla rolnictwa zbóż ozimych. Nawet niewielkie wahania wieloletnich średnich temperatur potrafią znacząco je podwyższać lub obniżać. Wnioski zawarte w pracy sformułowano w oparciu o informacje zawarte w źródłach przede wszystkim o charakterze skarbowym, do tej pory przez historyków klimatu niedoceniane. Analizę zachodzących w poszczególnych osadach zmian przeprowadzono z kolei posługując się metodyką stosowaną przez historyków osadnictwa. Efektem zaprezentowanych niżej badań jest generalny wniosek o istnieniu w analizowanym okresie powszechnego zjawiska narastania na obszarach karpackich elementów modelu gospodarczego funkcjonowania wsi opartego na hodowli. Odbywało się to kosztem ograniczania lub czasami nawet eliminowania zajęć rolniczych. Stanowiło to decydujący powód dla którego poszczególni wielcy właściciele ziemscy sprzyjali lub inicjowali kolonizację opartą na prawie wołoskim lub co najmniej na jego elementach. $Z$ tej przyczyny zwłaszcza XVI wiek stał się okresem gwałtownego rozwoju tego nurtu osadniczego w rejonach karpac- 
kich. Miało to poważne konsekwencje nie tylko dla gospodarki. W pracy zwrócono uwagę, że wprowadzanie zmian mogło się odbyć poprzez migracje obcej etnicznie ludności-zaznajomionej z tajemnicami wyspecjalizowanej hodowli, niedostępnej klasycznym rolnikom. Wśród przybyszów pojawili się również etniczni Wołosi. Jedną z konsekwencji tych wędrówek było też znaczne rozszerzenie w Małopolsce zasięgu prawosławia kosztem katolicyzmu.

Author: Maria Curie Skłodowska University, Insitute of History, Plac Marii Curie-Skłodowskiej 4A, 20-031 Lublin, Poland, e-mail: grzegjaw@poczta.onet.pl, ORCID iD: https://orcid.org/0000-0002-39625388

Keywords: Carpathians, ius Valachicum, pastoral economy, colonisation, climate, Little Ice Age

Balcanica Posnaniensia. Acta et studia, XXV, Poznań 2018, Wydawnictwo Instytutu Historii UAM, pp. 251268, ISBN 978-83-65663-94-8, ISSN 0239-4278. French text with summaries in English and Polish.

doi.org/10.14746/bp.2018.25.14

Il n'y a pas d'unanimité en ce qui concerne la période initiale du Petit Âge Glaciaire (PAG) dans l'hémisphère nord. Les chercheurs dans ce domaine prennent en considération une période très vaste à partir de 1250 jusqu'en 1550 . Toutefois, il existe un consensus concernant la définition de la fin du PAG qui eut lieu dans la deuxième moitié du XIXe siècle. Plusieurs arguments physico-géographiques font situer le début de ce phénomène dans les zones les plus élevées des Carpates et celles des Alpes vers 1400 . Il ne s'agissait pourtant pas d"un temps unique de la détérioration du climat. On observe une concentration dans le temps des anomalies climatiques associées à d'autres phénomènes définis comme catastrophes naturelles, ce dont la phase principale correspondait à la période entre 1550 et 1770 . Mise à part cela, le PAG se caractérisait par de considérables fluctuations climatiques au long de décennies (périodes de 20 à 40 ans caractérisées par une succession alternée de cycles stables et ceux où des phénomènes extraordinaires se produisaient avec une grande fréquence), ou même, au long d'une année. Dans les Tatras, chaîne la plus élevée des Carpates, la période froide la plus longue est datée entre 1576 et $1675^{1}$, ce qui est confirmé par des analy-

${ }^{1} \mathrm{~J} . \mathrm{M}$. Grove, The initiation of the „Little Ice Age” in regions round the North Atlantic, "Climatic Change» 48 : 2001, nr 1, s. 53-82 ; A. Kotarba, Mała epoka lodowa w Tatrach Wysokich, [Le Petit Âge Glaciaire dans les Hautes Tatras], w : VII Zjazd Geomorfologów Polskich. Wspótczesna ewolucja rzeźby Polski [VII Congrès des Géomorphologues Polonais, L’Évolution contemporaine du relief de la Pologne], red. A.Kotarba, K. Krzemień, J. Święchowicz, Kraków 2005, s. 50-65; A. Kotarba, „Zdarzenia geomorfologiczne w Tatrach Wysokich podczas małej epoki lodowej" [Événements géomorphologiques dans les Hautes Tatras pendant le Petit Âge Glaciaire], dans Rola Małej Epoki Lodowej w przekształcaniu środowiska przyrodniczego Tatr, [Le rôle du Petit Âge Glaciaire dans la transformation de l'environnement naturel des Hautes Tatras] A. Kotarba, éd. (Warszawa: PAN IGiPZ, 2004), 10; T. Niedźwiedź, „Rekonstrukcja warunków termicznych lata w Tatrach od 1550 roku” [Reconstruction des conditions thermiques de l'été dans les Tatras], dans Rola Małej Epoki Lodowej, [Le rôle du Petit Âge Glaciaire dans la transformation de l'environnement naturel des Hautes Tatras], s. 57-88. 
ses des glaciers alpins ${ }^{2}$. Selon Henryk Maruszczak, des crises alimentaires se produisaient dans de différentes zones de l'hémisphère nord, pourtant elles touchaient surtout les populations qui habitaient des terrains montagneux ou ceux à proximité des montagnes. Il s'agissait donc des terrains marginaux des zones et des étages de végétation altitudinaux, puisque ceux-ci sont vulnérables à de légères fluctuations des indicateurs climatiques normaux ${ }^{3}$. Pour les habitants des zones situées à proximité des montagnes, pendant le PAG, la température moyenne pluriannuelle plus basse d'un seul degré par rapport à l'actualité ${ }^{4}$ pouvait entraîner de graves conséquences concernant leur manière d'exploitation. En pratique, cela conduisait au raccourcissement de la période de végétation, ce qui faisait baisser le niveau de l'étage supérieur de la culture des céréales d'hiver, en fonction des conditions locales, depuis quelques dizaines jusqu'à une centaine de mètres ${ }^{5}$. Vu que les cultures de printemps avaient un rendement plus petit, la substitution des cultures d'hiver par celles de printemps ne réduisait que partiellement les effets négatifs du refroidissement du climat. De même, dans les terrains situés plus bas, des calamités naturelles cycliques pouvaient faire produire des crises de l'agriculture, en particulier, à l'époque où la récolte moyenne, même si les conditions climatiques étaient stables, ne surpassait trois, ou bien, quatre grains sur un grain semé ${ }^{6}$.

${ }^{2}$ H. Holzhauser, M. Magny and H. J. Zumbuhl, Glacier and lake-level variations in west-central Europe over the last 3500 years, „The Holocene ” $15: 2005, \mathrm{nr} 6$, s. 797.

${ }^{3}$ H. Maruszczak, Tendencje sekularne $i$ zjawiska ekstremalne $w$ rozwoju rzeźby małopolskich wyżyn lessowych $w$ czasach historycznych [Tendances séculaires et phénomènes extrêmes dans l'évolution du relief des zones collinaires de loess en Petite-Pologne dans les temps historiques], „Czasopismo Geograficzne" 57 : 1986, nr 2, s. 271-288; H. Maruszczak, Zmiany środowiska w okresie historycznym [Changements environnementaux dans les temps historiques], w : Geografia Polski. Środowisko geograficzne [Géographie de la Pologne. Environnement géographique], red. L. Starkel, Warszawa 1999, s. 182 205.

${ }^{4}$ J.Luterbacher (et al.), European Seasonal and Annual Temperature Variability, Trends, and Extremes Since 1500, „Science” 303 (5663): 2004, s. 1500; J. A. Matthews and K. R. Briffa, The „Little Ice Age”: Re-Evaluation of an Evolving Concept, „Geografiska Annaler”, 87: 2004, nr 1, s. 21; P. Dobrovolný (et al.), Monthly, seasonal and annual temperature reconstructions for Central Europe derived from documentary evidence and instrumental records since AD 1500, „Climatic Change ”101: 2010, nr 1-2, s. 93.

${ }^{5}$ Actuellement, dans la région de Podhale, dans les terrains situés entre 400 et $600 \mathrm{~m}$, il est possible de cultiver des céréales d'hiver, du seigle en particulier, et même du blé, si les conditions climatiques et celles de sol sont très favorables. Cependant, au-dessus de $700 \mathrm{~m}$, les récoltes des céréales d'hiver et celles de l'orge de printemps ne sont jamais réussies. La période de végétation trop courte, une couche de neige très épaisse et qui ne disparaît que très tard font éliminer ces cultures (C. Guzik, Zmiany użytkowania ziemi i sposobów gospodarowania w rolnictwie Podhala [Changements dans l'exploitation du sol et pratiques agricoles dans la région de Podhale], w : Geografia i Sacrum [La Géographie et le Sacré], vol. 1, red. B. Domański, S. Skiba, Kraków 2005, s. 89).

${ }^{6}$ Pour la fin du XIVe et le début du XVe siècles, on a obtenu les mêmes résultats dans le cas du Royaume Tchèque, Angleterre et Provence (S. Chmielewski, Gospodarka rolna $i$ hodowlana w Polsce $w X I V i X V$ w. Studia z dziejów gospodarstwa wiejskiego [L'Agriculture et l'Élevage aux XIVe et XV siècles. Études sur l'histoire des pratiques agricoles], vol. 5 nr 2, red. J. Leskiewiczowa, Warszawa 1963, s. 110. 
La période indiquée dans le titre correspond non seulement au début et à l'étape la plus ancienne du PAG dans la partie des Carpates en question, mais aussi, au temps de la plus intense expansion de la colonisation basée sur le ius Valachicum. Le fonctionnement des villages dans un cadre juridique différent par rapport à l'état antérieur, des flux de populations appartenant aux groupes ethniques différents, ainsi que l'implantation d' un nouveau modèle économique des villages en étaient des conséquences. Les habitants de ces villages étaient en particulier des éleveurs spécialisés, dans une moindre mesure, agriculteurs, et même artisans ${ }^{7}$. Cette observation fait poser des questions sur les liens entre ces deux phénomènes. Est-ce que l'expansion de la colonisation valaque dans les Carpates Occidentales promue par des propriétaires terriens locaux fut une conséquence des changements climatiques négatifs qui faisaient, à leur tour, éliminer des agriculteurs autochtones? Ou bien, il n'y avait pas d' alternative à ce type de colonisation des Carpates et des terrains limitrophes? L'auteur de la description des biens royaux du capitaneatus de Sambor (Ruthénie de la Couronne) qui s'y connaissait bien sur les spécificités de l'exploitation dans les montagnes justifiait en 1568 l'expansion de la colonisation valaque directement par des conditions climatiques difficiles, et en particulier, par l' impossibilité de cultiver des céréales d'hiver nécessaires dans une économie typique qui se basait sur la production des céréales: « Les terrains du capitaneatus de Sambor sont surtout situés dans les montagnes où les céréales d'hiver ne poussent pas, puisque l'hiver est long et en automne il gèle très tôt $»^{8}$. Un climat rigoureux et un sol de qualité faible sont des caractéristiques fréquemment répétées dans les recueils des faits historiques concernant les montagnes, à partir de l'époque de Jan Długos ${ }^{9}$. Cependant, ces sources historiques n'ont qu'une importance limitée sur les recherches relatives à l'impact du PAG sur la colonisation des zones montagneuses. Elles ne font référence qu'à de cas séparés des anomalies climatiques, ou bien, elles contiennent des considérations générales applicables à tou-

${ }^{7} \mathrm{~J}$ 'ai abordé beaucoup de problèmes liés à différents aspects de la colonisation valaque en Pologne dans une monographie (G. Jawor, Aşezările de drept valah şi locuitorii lor din Rutenia Roşie în Evul Mediu târziu [Les villages de Ius Valachicum et leurs habitants en Ruthénie Rouge en Bas Moyen Âge], trad. G. Gavril-Antonosei, Jaşi 2013) et dans d'autres études dont la liste figure sur le site: http://www. terramedievalis.pl/index.php/p1/11-pracownicy/12-prof-dr-hab-grzegorz-jawor C' est là que je renvoie les lecteurs qui seraient intéressés par des observations plus détaillées.

${ }^{8}$ Recueil des documents émis dans le grand-duché de Lituanie dit Metryka Litewska conservé dans les Archives Centrales des Actes Anciens, IV, B, cote 22 folio $3 \mathrm{c}$ verso. Le texte original est en ancien polonais.

${ }^{9}$ On retrouve les mêmes motifs dans le texte de Jan Długosz sur les conditions climatiques dans les environs de Czorsztyn: Sunt agri steriles et frigora grandia diucius terram premunt, ita quod pauco tempore anni inibi laboratur ([Jan Długosz] Joannis Dhugosii Annales seu Cronicae inclicti Regni Poloniae. Liber nonus, éd. Z. Budkowa, J. Garbacik et coll.., Varsoviae 1978, s. 278, ainsi que dans la description d'un hiver rigoureux de 1490/1491 faite à Pilzno (en Petite-Pologne): In montibus autem et silvis alcior. Quo continuo casu nivis vero Valachi cum pecoribus obvallati periere in montibus aprique silvatici in gregem cumulati e silvis in villas et nivis mersione et inediis affluebant, necabanturque intra sepum vincula, dorcarumque multitudo nivibus pressa fuit (Spominki pilzneńskie 1486-1506) [Mémoires de Pilzno], éd. A. Bielowski, w : Monumenta Poloniae Historica, vol. 3, Kraków 1878, s. 248. 
tes les époques ${ }^{10}$. Aujourd'hui, le climat de ces contrées est aussi rigoureux, si l'on le compare à celui des plaines, les sols y sont peu productifs, les hivers sont prolongés etc. À l'époque contemporaine, des anomalies météorologiques se produisent aussi de temps en temps. Le problème réside plutôt dans leur fréquence qui ne fut pas définie par les sources provenant de la charnière du Moyen Âge et l'époque moderne. Il faut reconnaître que nous ne disposons pas d'informations écrites sur les observations météorologiques sur cette partie de l'Europe qui auraient été faites de façon régulière. C'est pour cette raison qu'un chercheur qui s'occupe de cette période-là doit recourir à un instrument qui n'était, jusqu'à présent, employé qu'assez rarement, cela veut dire, aux analyses des changements juridiques et économiques qui se produisirent dans des villages à caractère agricole (parfois très anciens, existant depuis XIIIe ou XIVe siècle) situés dans les régions montagneuses. Actuellement, cela est possible grâce à l'édition des dictionnaires historiques et géographiques relatifs à de différents terre et palatinatus de l'ancienne Pologne, lesquels contiennent toutes les informations conservées sur les localités présentes dans les sources jusqu'à la moitié du XVIe siècle.

À partir de la fin du XIXe siècle, les historiens polonais ${ }^{11}$, tchèques et slovaques ${ }^{12}$ se rendent compte d'une crise permanente qui touchait des groupes des centaines de villages à proximité des montagnes. En conséquence, ces villages étaient totalement ou partiellement abandonnés par les agriculteurs substitués par les bergers valaques. Ce qui est surtout intéressant, c'est que ces villages se situaient habituellement entre $400 \mathrm{~m}$ et $700 \mathrm{~m}$, c'est à dire dans des terrains particulièrement menacés par la dé-

${ }^{10}$ Les chercheurs dans le domaine du climat qui examinent les XVe et XVIe siècles disposent de sources écrites sur ce genre de phénomènes recueillies dans A. Walawender, Kronika klęsk elementarnych Polsce i krajach sasiednich w latach 1450-1586 [La Cronique des catastrophes naturelles en Pologne et pays voisins entre 1450 et 1586], Lwów 1932.

11 W. Bębynek, Starostwo muszyńskie. Własność biskupów krakowskich [Le Capitaneatus de Muszyna. Propriété des évêques de Cracovie], „Przewodnik Naukowy i Literacki. Dodatek do „, Gazety Lwowskiej”, 42: 1914, nr 1, s. 16; E. Długopolski, Przyczynki do osadnictwa wołoskiego w Karpatach [Contributions à l'étude de la colonisation valaque dans les Carpates]. Sprawozdanie Filii c.k. Gimnazjum św. Jacka w Krakowie, Kraków 1916, s. 7; S. Kuraś, Osadnictwo i zagadnienia wiejskie w Gorlickiem do połowy $X V I w$. [Colonisation et problématique de campagne dans la région de Gorlice jusqu'à la moitié du XVIe siècle], w: Nad rzeka Ropa. [Sur les rives de Ropa] vol. 3. Szkice historyczne, red. Z. Żarnecka, Kraków 1968, s. 66-69; Z. Perzanowski, Przegląd najstarszych dziejów osad wiejskich regionu krośnieńskiego (stownik geograficzno-historyczny) [Revue de l'histoire ancienne des villages de la région de Krosno (dictionnaire historique et géographique)], w: Krosno. Studia z dziejów miasta i regionu [Krosno. Études sur l'histoire de la ville et de la région], vol. 2 (1918-1970), red. J. Garbacik, Krosno1973, s. 389, 404; K. Pieradzka, Na szlakach Łemkowszczyzny [Sur les sentiers des Lemkos], Kraków 1939, s. 60 - 62; A. Prochaska, Jaśliska, miasteczko i klucz biskupów przemyskich [Jaśliska. Localité et complexe des propriétés des évêques de Przemyśl], „Przewodnik Naukowy i Literacki. Dodatek miesięczny do „Gazety Lwowskiej", 17: 1889, nr 1, s. 62.

12 J. Beňko, Osidlenie severného Slovenska [Colonisation en Slovaquie du Nord], Košice 1985, s. 33, 81;V. Chaloupecký, Valaši na Slovensku [Les Valaques en Slovaquie], Praha 1947, s. 31; J. Macůrek, Valaši v západnich Karpatech v 15-18. Stoletni [Les Valaques dans les Carpates occidentales], Ostrava 1959, s. 59. 
térioration du climat. Il convient de rappeler qu'ils correspondaient à l'étage supérieur des cultures des céréales d'hiver. On expliquait souvent ce phénomène par le fait que les personnes responsables de l'initiation de l'action colonisatrice ne connaissaient pas suffisamment les conditions climatiques typiques pour les montagnes, ou bien, par l'incapacité de s'adapter des agriculteurs qui provenaient des plaines et des plateaux (terrains situés sur les altitudes entre 200 et $500 \mathrm{~m}$ ). Les instruments de travail et méthodes de production qui leur étaient accessibles y paraissaient peu utiles. Quelques opinions présentées ci-dessus trouvent leur confirmation dans des sources. Le village Piosek (aujourd'hui Písek en République Tchèque), antérieurement, à l'intérieur des frontières du Duché de Cieszyn, reçut le ius Theutonicum en 1466. Les agriculteurs qui y habitaient devaient faire face aux problèmes résultant des sols pierreux. C'était la raison pour laquelle des bergers valaques vinrent à la moitié du XVIe siècle et chassèrent peu à peu la population locale ${ }^{13}$. L'expulsion des agriculteurs du village Śmiłowice (Smilovice en tchèque) situé dans cette zone eut la même cause ${ }^{14}$. Wola Niżna, à son tour, village situé dans l'ancienne Terre de Sanok en Ruthénie de la Couronne passa du ius Theutonicum au ius Valachicum à cause, non seulement des sols peu productifs, mais aussi en raison de la proximité des montagnes et des vallées étroites où la culture de la terre s'avéra trop difficile ${ }^{15}$. Il est alors indiscutable que la crise du nombre indéfini de villages fut due à des conditions naturelles et non pas aux changements du climat qui ne s'intensifièrent qu'après la fondation de ces villages. Il faudrait aussi qu' on prenne en considération des cas des mouvements des populations des vallées vers les villages valaques situés dans les montagnes pour des raisons politiques et non pas économiques. Les agriculteurs d'Ustroń (le Duché de Cieszyn) se

${ }^{13}$ I. Panic, Śląsk Cieszyński w początkach czasów nowożytnych (1528-1653) [La Silésie de Cieszyn au début de l'époque moderne]. Dzieje Śląska Cieszyńskiego od zarania do czasów wspótczesnych, [Histoire de la Silésie de Cieszyn depuis ses origines jusqu'à l'époque moderne] vol. 3, Cieszyn 2011, s. 204; Macůrek, Valaši, s. 363, 375.

${ }^{14}$ C'est en 1460 qu'on retrouve pour la première fois dans les sources écrites le nom de ce village situé dans le duché de Cieszyn. À la fin du Moyen Age, il faisait partie des propriétés du duc (I, Panic, Śląsk Cieszyński w średniowieczu (do 1528 roku) [La Silésie de Cieszyn au Moyen Âge (jusqu'en 1528)]. Dzieje Ślaska Cieszyńskiego od zarania do czasów wspótczesnych [Histoire de la Silésie de Cieszyn depuis ses origines jusqu'à l'époque moderne], vol. 2, Cieszyn 2010, s. 335. Le responsable de la colonisation de Śmiłowice appelé Smyl de Gutów, une localité plus ancienne où il fut venu du Sud. Tout au moins au début du XVIIe siècle, à Smiłowice et à beaucoup d'autres villages de Beskides vinrent les populations du Sud et de l'Est. Elles apportèrent les compétences dans le domaine de l'économie intensive pastorale. Les paysans de Śmiłowice faisaient paître leurs troupeaux dans les environs des montagnes Godula et Ropicznik. (F. Popiołek, Historia osadnictwa w Beskidzie Śląskim [L'Histoire de la colonisation dans les Beskides de Silésie], Katowice 1939, s. 213-215.

${ }^{15}$ En 1454, Nicolas, l'évêque de Przemyśl, en renouvelant la location du village Radinc, le nomma Iwanszówka, le village fonctionnait selon le ius Theutonicum. En 1542, le propriétaire du village, évêque de Przemyśl fit passer Wola Niżna au Ius Valachicum. À partir de cette époque-là, tous les habitants du village devaient donner comme prestation d'un tan 4 moutons, du fromage valaque, des sousventrières et payer la dîme des porcs. (A. Fastnacht, Stownik historyczno-geograficzny ziemi sanockiej $w$ średniowieczu, [Dictionnaire historique et géographique de la Terre de Sanok en Moyen Âge] vol. 3 $(O-\dot{Z})$, Kraków 2002, s. 234. 
réfugièrent dans les montagnes voisines en fuyant ainsi les pillages pendant la Guerre de Trente Ans. Tout au long du XVIIe siècle, ils furent joints par des bergers professionnels venus des terrains au Sud des Carpates (appelés Ruman et Rumański) qui exploitaient des prés de montagnes et construisaient des cabanes où il vivaient en été ainsi qu'ils produisaient du fromage et autour desquelles ils faisaient paître des chèvres et des moutons ${ }^{16}$.

Néanmoins, les villages qui changèrent de statut juridique et de profil de la production agricole, sans qu'on ait d'informations directes sur ce processus, restent plus nombreux. Szlachtowa $(524 \mathrm{~m})^{17}$, village situé au pied des Piénines en est un exemple typique. Il constitue (avec des villages voisins Jaworki, Biała Woda et Czarna Woda) le territoire le plus occidental de la terre historique des Lemkos. Dans la réalité $\mathrm{du}$ XVIe siècle, ces villages correspondaient aux limites occidentales du christianisme orthodoxe en Petite-Pologne. Le village de Szlachtowa est mentionné par les sources à partir, au moins, de 1469. Szlachtowa et les villages voisins étaient peuplés, au $\mathrm{XVe}$ siècle par la population polonaise. Les références sur les sculteti sont une preuve de ce qu'ils furent fondés à la base du ius Theutonicum. Au début du XVIe siècle, à Szlachtowa, eut lieu une crise dans le domaine de la colonisation. Les paysans qui y habitaient jusqu'alors l'abandonnèrent tous, en 1519 cette localité fut décrite comme village sans résidents. Certainement, les Valaques y apparurent après cette datelà. En 1581, on paya l'impôt de quatre exploitations valaques (y comprises celles de Jaworki ${ }^{18}$. On a plus d'informations sur les premiers habitants du village royal de Królowa $(450 \mathrm{~m})$ dans le capitaneatus de Sącz. Królowa fut mentionné comme village agricole, habité par des Polonais déjà en 1504. Avant 1544, il se produisit une crise: les paysans vendirent leurs exploitations (sans avoir obtenu l'acceptation de la part du capitaneus comme représentant du roi, laquelle aurait été exigée normalement) aux Valaques dont le chef s'appelait Zain et fut issu d'un ancien village valaque Bielanka dans les environs de Gorlice. Il y a des indices qui font penser que les habitants précédents de Królowa partirent vivre aux terrains éloignés quelques kilomètres à peine et ils fondèrent un village sur les rives du même cours d'eau, lequel, plus

\footnotetext{
${ }^{16}$ Panic, Śląsk Cieszyński w średniowieczu, s. 296; Popiołek, Historia, s. 221-225.

17 Toutes les altitudes au-dessus du niveau de la mer mentionnées dans cette étude se réfèrent au fond des vallées où se situent les villages en question.

${ }^{18}$ Stownik historyczno-geograficzny województwa krakowskiego w średniowieczu [Dictionnaire historique et géographique du Palatinatus de Cracovie en Moyen Âge], (depuis: SHGWK), vol 1, Wrocław 1980-1986), s. 684; J. Czajkowski, Studia nad Łemkowszczyzna [Études sur les Terres de Lemkos], Sanok, 1999, s. 47; Źródła Dziejowe: Vol. 14: Polska XVI wieku pod względem geograficzno-statystycznym opisana [Description de la Pologne du XVIe siècle faite du point de vue géographique et statistique], wyd. A. Pawiński, Warszawa 1886 (depuis: ŹD 14), s. 147. De même, le village de Szczawnik (600 m) dans les environs de Muszyna existait déjà en 1391. C'est à cette époque-là qu'il fut mentionné entre d'autres villages transmis par le roi Ladislas II Jagellon à l'Évêché de Cracovie (SHGWK 1, 553). Le village cessa d' exister, puisqu'en 1516 l'évêque Jan Konarski permit à Waszko Wołoch de fonder Szczawnik (appelé Konary à l'époque). En 1575, l'évêque Franciszek Krasiński accepta le privilège mentionné, alors, on peut croire que ce processus connut des obstacles. (Bębynek, Starostwo, s. 619-620).
} 
tard, reçut le nom de Królowa Polska. Il était localisé $50 \mathrm{~m}$ plus bas, dans des terrains plus favorables du point de vue de l'exploitation agricole ${ }^{19}$. On pourrait en donner plus d'exemples. Parfois, ces changements touchaient même de petits centres urbains de ius Theutonicum allemand qui, sous influences des Valaques devenaient des villages des bergers. C'est le cas, entre autres, de la localité Tylicz $(580 \mathrm{~m})$ qui possédait les privilèges urbains depuis la charnière du XIVe et XVe siècles. Dans la deuxième moitié du XVe siècle, on observait l'importance croissante de l'élément valaque entre ses habitants. Cela était parallèle au processus de la perte des fonctions urbaines, ce qui fut confirmé en 1612 par la fondation de Tylicz sur l'endroit appelé Miastko. On constata que Tylicz fut fondé dans les terrains de Miastko qui possédait auparavant les privilèges urbains, mais qui fut redevenu village. En se basant sur le ius Valachicum les habitants de Tylicz fondèrent Szczawnik en 1516 et, en 1547, Krynica. Jusqu'en 1411 il exista là une église détruite par les troupes hongroises. C'était à Miastko qu'en 1461, un pope vivait, en 1491 un jeune prêtre, fils du pope de Miastko fut mentionné. En 1612, à l'occasion de la fondation de Tylicz, on constata que les habitants de cette localité eurent jadis abandonné le catholicisme romain et se furent convertis à la confession orthodoxe ${ }^{20}$. Ce n'est que sur l'ancien palatinatus de Cracovie (en PetitePologne) que l'on a reçu des informations plus détaillées relatives à 34 localités qui connurent les mêmes transformations au long du XVe et XVIe siècles. 13 entre ces localités ${ }^{21}$ se situaient sur les altitudes qui ne surpassaient pas $400 \mathrm{~m}$. Un groupe de 21 villages $^{22}$ localisés sur les altitudes entre 400 et $700 \mathrm{~m}$ s'en distinguait de façon évidente.

19 SHWGK 3, s. 159-160; Czajkowski, Studia, s. 49-50.

20 SHGWK 4, s. 288-290.

${ }^{21}$ Il s'agit de Biertowice (SHGWK 1: 106; Акты Виленской археографической комиссии: vol 25: Инвентарии и разграничительные акты [Actes de la Commission Archéographique de Vilnius. Vol. 25: Inventaires et délimitations], depuis: AVK 25, Вильна 1898, s. 447, 477) ; Chocznia (SGHWK 1, s. 349; J. Putek, Miłościwe pany i krnąbrne chłopy włościany [Seigneurs cléments et paysans désobéissants], Warszawa 1959, s. 120,129); Izdebnik (SHGWK 2, s. 190; AVK 25, s. 444-445, 477) ; Sułkowice (SHGWK 3, s. 426; AVK 25, s. 449-450, 477) ; Wola Gabońska (SHGWK 1: s. 509,688, 689; Sz. Morawski, Sądecczyzna za Jagiellonów z miasty spiskiemi i księstwem oświęcimskim [La région de Sącz à l'époque des Jagellons avec les villes de Spisz et le duché d'Oświęcim ], vol. 2, Kraków 1865 , s. 301-303); Rudnik (SHGWK 2, s. 147; AVK 25: s. 447-448, 477; Lustracja województwa krakowskiego 1564 [La description des biens royaux dans le palatinatus de Cracovie], wyd. J. Małecki, vol. 1, Warszawa 1962 -depuis: LWK), s. 203 ; Harbutowice (SHGWK 2, s. 146; AVK 25, s. 447, 477); Jachówka (SHGWK 2, s. 193; LWK 1, s. 205-206; ŹD 14, s. 47) ; Jasienica (SHGWK 2, s. 246; LWK 1, s. 209-210; AVK 25, s. 477) ; Juszczyn (SHGWK 2, s. 348-349; LWK 1, 211; ŹD 14, s. 47) ; Maków Podhalański (SHGWK 4, s. 45; LWK 1, s. 212; AVK 25, s. 466-467) ; Rozdziele (Metryka Koronna w Archiwum Głównym Akt Dawnych $w$ Warszawie [Recueil des documents émis par la Couronne dit Metryka Koronna conservé dans les Archives Centrales des Actes Anciens] - depuis: MK, cote 44, s. 497-499; Czajkowski, Studia, s. 54) ; Trzebunia (I. T. Baranowski, U stóp Babiej Góry [Au pied de Babia Góra], « Przegląd Historyczny » 20 : 1916, nr 1, s. 88; SHGWK 2: s. 147, 349; SHGWK 3: s. 427; LWK 1: s. 212; AVK 25: s. 477).

22 Il s'agit de: Binczarowa (SHGWK 1: s. 94), Chyrowa (SHGWK 2: s 154-155; Archives du Trésor de la Couronne dans les Archives Nationales des Actes Anciens à Varsovie), depuis: ASK, I, 1: k. 434; Perzanowski, Przegląd, s. 389), Mszana (J. Czajkowski, Dzieje osadnictwa historycznego na Podkarpaciu 
Il faut noter que dans le premier groupe, il y avait des villages desquels les agriculteurs ne furent pas éliminés complètement et dans lesquels les bergers valaques ne constituaient qu'une minorité. Izdebnik $(268 \mathrm{~m})$ était un village royal situé dans le capitaneatus de Lanckorona. Dans les sources, ce village est mentionné depuis 1335. Il est sûr qu'au XIVe siècle déjà, le ius Theutonicum y existait. L'un de ses sculteti Więcesław (mentionné entre 1362 et 1377) était membre du tribunal suprême de ius Theutonicum à Cracovie. Il est possible qu'au XVIe siècle des bergers valaques soient venus à Izdebnik, ou bien, des agriculteurs acquirent des idées caractéristiques pour l'économie pastorale qui se basait sur le ius Valachcum. À la lueur de l'inventaire du capitaneatus de 1646, mis à part les agriculteurs qui pratiquaient aussi l'artisanat lié aux activités sylvicoles, une partie de la population s'occupait du pâturage. À cause de cela, ils étaient obligés à payer, le jour de Saint Jacques, 3 gros par mouton, rendre un mouton sur 50 ou en payer l'équivalent en monnaie. Une fois par an, avant de partir avec les troupeaux aux pâturages d'altitude, les bergers devaient soumettre au comptage tous les animaux. Si l'on constatait qu'ils en faiaient paître plus qu'ils n'en avaient présenté au comptage, ils devaient, à titre de pénalité, rendre 12 béliers. En plus, les animaux qui ne figuraient pas dans l'inventaire étaient confisqués. On choisissait le wojewoda valaque (le chef d'un ensemble de villages valaques) qui assumait la responsabilité quant au déroulement régulier du pâturage. En plus, ils étaient obligés à rendre 4 grands fromages valaques de haute qualité ${ }^{23} .8$ autres villages situés dans le même ensemble des biens se développaient selon le même schéma, à savoir, il s'agit de: Biertowice (255 m n.p.m.), Chocznia (288), Sułkowice (294), Rudnik (323),

i jego odzwierciedlenie w grupach etnicznych [1'Histoire de la colonisation dans les Précarpates et ses reflets dans les groupes ethniques], w : Łemkowie w historii i kulturze Karpat [Lemkos dans l'histoire et la culture des Carpates], red. J. Czajkowski, , vol. 1, Rzeszów 1995, s. 107; Akta grodzkie i ziemskie z czasów Rzeczypospolitej Polskiej z Archiwum tak zwanego bernardyńskiego we Lwowie w skutek fundacyi śp. Aleksandra hr. Stadnickiego [Acta castrensia et terrestria de l'époque du Royaume de Pologne dans les Archives dits des bernardins à Lwów, fondation du feu Aleksander comte Stadnicki], depuis: AGZ, vol. 11, Lwów 1894, nr 1005, Dokumenty polskie z archiwów dawnego Królestwa Węgier [Documents polonais des archives de l'ancien Royaume de Hongrie], depuis: DP, wyd. S. Sroka: vol. 2: Dokumenty z lat 1451-1480 [Documents de la période 1451-1480], Kraków 2000, nr 228; ASK, I, 1, k. 426), Grzechynia (SHGWK 2, s. 114, LWK 1, s. 36; ŹD 14, s. 47), Jaworze (Czajkowski, Studia, s. 36; M. Dobrowolska, Procesy osadnicze $w$ dorzeczu Wistoki i Biatej Dunajcowej w tysiacleciu [Processus colonisateurs dans le bassin hydrographique de Wisłoka et celui de Biała Dunajcowa dans le millénaire], Kraków 1985, s. 144145, ŹD 14, s. 122), Męcina Wielka (SHGWK 4: s. 272, DP 5: nr 1079), Mszana Górna (SHGWK 1, s. 555 , LWK , s.152), Jaszkowa (SHGWK 2, s. 269, SHGWK 4s. 189) Królowa Górna (voir la note 20), Bogusza (SHGWK 1, s. 94, A. Stadnicki, O wsiach tak zwanych woloskich na pótnocnym stoku Karpat [À propos des villages dits valaques sur les versants nord des Carpates], Lwów 1848, s. 83-85, Szlachtowa (voir la note 18), Wawrzka (Czajkowski, Studia, s. 50-51, Bębynek, Starostwo, s. 620), Żegiestów (Bębynek, Starostwo, s. 622-623), Tylicz (note 20), Biała Woda (Czajkowski, Studia, s. 46-47), Jaworki (SHGWK 2, s. 278; Czajkowski, Studia, s. 46-47; ŹD 14, s. 147), Szczawnik (note 18), Waksmund (,Przywileje soltysów podhalańskich” [Privilèges des sculteti de la région de Podhale], wyd. E. Długopolski, „Rocznik Podhalański”, 1: 1914-1921, s. 11; LWK 1, s. 47), Łosie (SHGWK 3, s. 973; ŹD 14, s. 120), Muszynka (Czajkowski, Studia, s. 25, 84, 91), Szaflary (SHGWK 1, s. 638-639; LWK 1, s. 148-149).

${ }^{23}$ SHGWK 2, s. 190; AVK 25, s. 444-445, 477. 
Harbutowice (361), Jachówka (387), Maków Podhalański (364), Trzebunia (397)²4. Il faut observer que tous les villages mentionnés ci-dessus étaient localisés dans la partie occidentale de la Petite-Pologne, c'est-à-dire, à l'extérieur des terrains touchés par une intensive colonisation valaque qui datait du XVe siècle. Ce n'est que très rarement que des Valaques ethniques y venaient. C'est pourquoi on ne dispose pas d'informations à propos des villages qui auraient fonctionné selon un modèle classique de cette coutume juridique. Les éléments confirmés de ius Valachicum sont tardifs du point de vue chronologique (la deuxième moitié du XVIe siècle ou la première moitié du XVIIe siècle). Leur apparition ne parait être que l'effet des emprunts et inspirations indirectes $^{25}$. Les deux autres cas (Wola Gabońska $-330 \mathrm{~m}$ et Rozdziele - $351 \mathrm{~m}$ ) concernent la fondation des villages valaques, de petites dimensions, qui existaient à côté des villages agricoles plus anciens. Le cas de la seconde localité mentionnée ci-dessus est particulièrement intéressant. Elle fut fondée dans les terrains d'un village plus ancien Lipinki (l'ancien districtus de Biecz) habité par des Polonais. Le village fonctionnait selon le ius Theutonicum depuis le XIVe siècle, il possédait une église paroissiale ${ }^{26}$. $\mathrm{Au}$ début du XVIe siècle, les agriculteurs abandonnèrent la partie de ce village située à côté du Mont Wapienny: "dans cette partie du village il y avait des demeures désertes où les paysans polonais furent morts ou d'où ils eurent fui'. C'est la raison pour laquelle, en 1530, le roi accepta la vente d'un tan abandonné et celle du droit à défricher des terrains pour y installer un jardin à Piotr Biela, un riche campagnard provenant de Mszana valaque. La valeur de la transaction était de 20 florins hongrois ${ }^{27}$ . De nouveaux gens vinrent, aussi bien des Valaques comme des Ruthènes: "hominibus quibuscumque tam Valachis quam Ruthenis". Les nouveaux colonisateurs, ce qui est intéressant particulièrement, reçurent l'autorisation à construire une église ortho-

24 Voir la note 21.

25 Dans les Carpates occidentales, les limites de la colonisation valaque „classique” correspondaient, comme le démontrent les recherches, à la ligne qui allait de la chaîne des Petites Piénines (Ruś Szlachtowska), par les versants occidentaux des Gorce, vers la chaîne des Beskide Wyspowy. À l'ouest de cette ligne, il manque de structures paroissiales de l'Église orthodoxe, confession qui faisait distinguer les Valaques parmi la population locale. Les villages touchés par des influences indirectes de cette coutume étaient habités par les catholiques et, en particulier dans le cas de la Silésie de Cieszyn, par les protestants. Dans quelques régions, les paysans créaient de très complexes communautés ethniques. En Petite-Pologne de l'Ouest et en Silésie, des villages étaient peuplés par des bergers valaques, à côté desquels vivaient des paysans polonais, slovaques et hongrois (Popiołek, Dzieje, s. 170-172; S. Szczotka, Studia z dziejów prawa wołoskiego $w$ Polsce [Études sur l'histoire du droit valaque en Pologne], "Czasopismo Prawno-Historyczne", 2: 1948, s. 355.

26 SHGWK 3, s. 628-633.

27 En 1369, le village Mszana dans le districtus de Biecz fut fondé sur la base du ius Theutonicum. À cette époque-là, il fut peuplé par des Polonais. L'affluence des Valaques eut lieu au XVe siècle, car, en 1437, un tel „Fyed” et ses 4 compagnons furent accusés d'un vol (AGZ 11, nr 1005). En 1468, un Valaque Jaszko de Mszana fut enregistré par des sources (DP 2, nr 228). En 1506, le village fut dénommé Mssana Walaska. En 1536, on y paya la taxe de 6 tan (unité de mesure de superficie), un moulin et une église orthodoxe, et, en 1581, des 18 exploitations agricoles dont l'une appartenait à un kniaź, et une autre à un pope (Perzanowski, Przegląd, s. 404; Czajkowski, Dzieje, s. 107; ASK, I, 1, k. 426). 
doxe, et en même temps, ils se garantirent le droit à ne pas se soumettre à l'autorité du curé local (plebanus): "Permittimus etiam ipsis incolis et kmethonibus ibudem locatis et locandis synagogam Ruthenicam in quocumque loco oportuno per tenutarium nostrum demonstrando erigere et construere, poponemque Ruthenum fovere et ei honorem et fructum debitum more ipsorum exhibere, sine preiudicio pastoris ecclesiae ibidem in Lipinki”. Avec le temps, ces nouveaux venus se séparèrent en créant un village à part. Cette division se fit certainement dans un climat conflictuel en relation avec les autres habitants de Lipinki, c'est-à-dire, avec les Polonais: "les Valaques ne s'entendaient pas avec les anciens habitants ni du point de vue de la religion, ni en ce qui concerne des coutumes" 28 .

Les relations entre une colonisation typique à caractère agricole d'une part et la colonisation valaque sur les altitudes qui ne dépassent pas $400 \mathrm{~m}$ au-dessus du niveau de la mer ont été déjà décrites dans des études antérieures. Il ne faut que rappeler ici leurs effets. Les facteurs économiques exerçaient une influence décisive. Le refroidissement climatique (le PAG) joua un rôle réduit. L'évolution positive et stable de la demande de produits agricoles observée tout au long du XVIe siècle (l'essor du marché des céréales surtout, mais aussi la demande croissante de produits de la forêt et de ceux de l'économie pastorale) eut une influence considérable et ambiguë sur le processus de la colonisation valaque des terrains en question. On liquidait des villages situés sur des terres fertiles, lesquels dataient du XVe siècle, où l'on fondait de grandes exploitations agricoles qui produisaient des céréales et où on imposait une corvée régulière en faveur du propriétaire. Elle était absente dans le ius Valachicum. La protection des forêts précieuses devint plus intense, ce qui entraîna l'interdiction de faire paître des troupeaux. La colonisation valaque était dirigée vers des zones périphériques et marécageuses, dont les sols rendaient peu, ou bien, elles étaient, pour d'autres raisons, difficilement cultivables de manière intensive. L'installation de familles ou de petits groupes de bergers dans d'anciens villages agricoles était une méthode répandue d'augmenter les recettes des terres. Dans presque chaque village, il y avait des prairies humides et des terres non cultivées, puisque peu attractives du point de vue agricole. D'autre part, il y avait aussi des terres cultivables où, après la saison de végétation, on pouvait introduire de petits troupeaux ${ }^{29}$. Il ne fait aucun doute que les indi-

${ }^{28}$ MK 44. k 497-499; LWK 1, s. 143; Czajkowski, Studia, s. 54. Le nom du village „Rozdziele” provient des verbes polonais oddzielić, rozdzielić qui signifient „délimiter”, „tracer les limites”

${ }^{29} \mathrm{~K}$. Dobrowolski, Zderzenie kultury rolniczej z pasterska [Le Choc de la culture agraire et la pastorale, „Sprawozdania z Czynności i Posiedzeń PAU”, 5: 1939, s. 192; В. Ф. Инкін, Крестьянский общинный строй в галицком Прикарпатье. (Опыт сравнительного изучения поземельных союзов). Автореферат диссертации, [Le système de l'administration des villages par les paysans dans les Précarpates de Halicz. L'exposé liminaire de la thèse de doctorat], Львов, 1978. s. 17-18; A. Janeczek, Osadnictwo pogranicza polsko-ruskiego. Województwo bełskie od schytku XIV do początku XVII w. [La colonisation de la zone frontalière polono-ruthène. Le palatinatus de Bełz depuis la fin du XIVe siècle jusqu'au XVIIe siècle], Wrocław 1991, s. 157; G. Jawor, Northern Extent of Settlement on the Wallachian Law in Medieval Poland, Res Historica» 41 : 2016, s. 35-49 ; G. Jawor, Aşezările, s. 198-203; G. Jawor, Волоське осадництво на теренах Розточчя у пізньоту середньовіччі [La colonisation valaque dans 
ces de ce genre eurent une influence décisive sur l'introduction de quelques éléments du ius Valachicum dans le cas des terrains décrits ci-dessus.

Comme on a déjà indiqué, la variabilité des conditions climatiques se faisait particulièrement sentir dans la zone de transition entre les terrains montagneux et les sousmontagneux, c'est-à-dire, sur les altitudes au-dessus de 400 mètres, où, même, un refroidissement peu signifiant déterminait la réussite des cultures des céréales. Sans rendements provenant de cette source, une classique économie agricole était impossible. La comparaison des circonstances de l'installation des Valaques dans d'anciens villages agricoles ${ }^{30}$ avec les terrains situés sur les altitudes inférieures et que l'on vient de mentionner peut conduire à des conclusions intéressantes. Ce n'est que dans trois cas (Mszana Górna - 411 mètres, Waksmund - 596 mètres, Szaflary - 640 mètres), on pourrait observer le modèle des changements causés par la colonisation, lequel consistait à ce que la population locale acquérait des éléments du ius Valachicum, ou bien, à ce que des individus qui s'occupaient du pâturage s'établissaient à l'intérieur des villages. Dans le cas des autres 20 villages soumis à l'analyse, les sources conservées mettent en relief un échange important près de Muszyna, ou même, complet de population, ce que l'on n'a pas encore pris en considération. Les Valaques venaient s'établir, ce qui était caractéristique, dans les villages qui avaient été abandonnés par les agriculteurs. On peut s'y servir de l'exemple du village Żegiestów (520 mètres) localisé à Muszyna, dans les biens de l'évêque de Cracovie. Żegiestów fut mentionné dans les sources en 1391 déjà. Ensuite, à un certain moment indéterminé, il se dépeupla. Sa dénomination ne se conserva que pour désigner un champ abandonné, où, en 1575, l'évêque Franciszek Krasiński autorisa un sujet d'un village valaque Andrzejówka à fonder Żegiestów ${ }^{31}$. Le village Łosie (640 mètres). En 1359, le roi Casimir III de Pologne, dit le Grand attribua des terres depeuplées et détruites, y compris le village Łosie, à Jan Gładysz. Postérieurement, le village fonctionna selon le ius Theutonicum. En 1480, le scultetia du village Łosie fut acqui par Piotr dit Paszkowic qui provenait, ce qui est digne d'être souligné, de Bednarki, village concerné à cette époque-là, par la colonisation valaque ${ }^{32}$. Ce n'est que dans le privilège suivant, émis en 1524 en fa-

le région de Roztocze au bas Moyen Âge], „Вісник Львівського Үніверситету“. Серія історична 35/36 2000, s. 58-75; G. Jawor, Wspótistnienie grup etnicznych na Rusi Czerwonej w XV-XVI wieku na przykladzie stosunku do społeczności woloskich [La cohabitation des groupes ethniques en Ruthénie Rouge aux XVe et XVI siècles d'après l'exemple de l'attitude envers les communautés valaques], „, Annales UMCS“, sectio F. Historia, 52/53 : 1997/1998, s. 53-65.

${ }^{30}$ Voir la note 22.

${ }^{31}$ Bębynek, Starostwo, s. 622-623.

32 Bednarka, propriété royale dans le capitaneatus de Biecz surgit dans les sources en 1401. Juste après, l'affluence des Valaques commença, vu que les sculteti s'appelaient Laczslaus Walachus (entre 1420 et 1426), Szandro (en 1426), Szymon Walach (en 1438) et le noble Szymek (en 1438). L'existence de l'économie pastorale dans ce village reste hors de doute, puisque le riche paysan appelé Borys (qui habitait à Bednarka) était le propriétaire d'un troupeau qui comptait 170 moutons (SHGWK 1, s. 34). En 1530, le roi autorisa Piotr Biel, riche paysan de Mszanka à installer des Valaques dans les terrains abandonnés de Bednarka (Pieradzka, Na szlakach, s. 109). 
veur de Waszko de Rychwałd (actuellement Owczary - 385 mètres) que l'on retrouve sans problème des éléments typiques pour le ius Valachicum ${ }^{33}$. L'émission du privilège mentionné fut justifiée par la destruction que le village eut connue pendant les années précédentes ${ }^{34}$. De temps en temps, le changement du profil ne se produisait pas par un seul acte, mais il s'agissait d'un processus prolongé qui pouvait durer des décennies. Grzechynia (413 mètres), village qui faisait partie des biens royaux, était présent dans les sources écrites à partir de 1432. Initialement, c'était un village agricole de ius Theutonicum. On peut le croire puisqu' en 1432 le scultetus Szymon y vivait. Il est probable que les changements du statut juridique et du profil économique du village commencèrent vers la moitié du XVIe siècle, car en 1558, on y signala la présence de 12 riches paysans et de 3 zarębnik ${ }^{35}$, catégorie de la population qui habitait fréquemment des villages valaques. On y observa aussi que les contributions étaient payées avec du fromage et le pâturage se faisait dans des forêts environnantes: "a pascuis suum in silvis nihil anno eodem provenit, quoniam silvae nullum fructum dederunt". Il semble que le processus de l'échange de la population se fit rapidement dans les années suivantes. En 1564, 13 riches agriculteurs continuaient à vivre dans ce village situé entre les montagnes, mais, en même temps, il y avait 27 (!) individus nouveaux. Le scultetia fut désigné comme complètement dépeuplé. En 1581, les zarębnicy valaques (24!) et 3 habitants pauvres qui n'avaient pas de bétail étaient les seuls contribuables. On ne nota pas la présence des agriculteurs typiques ${ }^{36}$.

Quoique nos considérations s'appuient jusqu'à présent sur les sources écrites concernant une partie des Carpates Occidentales (La Petite-Pologne du Sud), il est, sans doute, possible de noter les mêmes phénomènes qui se produisaient à grande échelle dans les autres zones montagneuses. Il est donc justifié d'avancer une thèse générale sur une modification importante des caractéristiques de la colonisation des terrains montagneux et ceux qui étaient situés à proximité des montagnes tout au long des XVe et XVIe siècles sous l'influence de la détérioration du climat (le PAG). Cette modification apporta des incidences à divers égards qu'il faudrait soumettre aux analyses scientifiques plus détaillées. Du point de vue de l'économie rurale, il est né-

${ }^{33}$ La présence documentée des Valaques à Rychwałd remonte à 1417. Auparavant, cela avait été probablement un village agricole, peuplé, au moins partiellement, par une population d'origine allemande ce qui est confirmé par le propre nom du village. À cette époque-là, on émit le privilegium locationis à un certain Klima - Zbiór dokumentów małopolskich. Vol. 1: Dokumenty z lat 1257-1420, [Recueil de documents de Petite-Pologne. Vol. 1: Documents depuis 1257 jusqu'en 1420], wyd. S. Kuraś, Wrocław 1962, nr 324.

34 SHGWK 3, s. 973.

${ }^{35}$ Le nom zarębnik désigne un groupe d'habitants des villages et il provient du substantif zarębek qui signifait originairement un petit champ dans les montagnes, effet du défrichement d'un fragment de la forêt (J. Kobylińska, Językowy obraz wsi beskidzkiej w XVII wieku na przykładzie nazw ziemi i jej mieszkańców w księgach gromadzkich wsi Kasina Wielka, [L'image linguistique de la campagne des Béskides au XVIIe siècle.. Étude basée sur les noms désignant les sols et les habitants employés dans les actes du tribunal du village Kasina Wielka] „Język Polski”, 79, vol. 4-5, (1996), s. 339-340.

36 SHGWK 2, s. 114; ŹD 14, s. 47. 
cessaire de mentionner ici la limitation des activités agricoles en faveur des activités pastorales, la propagation du ius Valachicum, un nouveau système juridique de l'organisation des villages, les migrations des populations et les changements des frontières entre les ethnos et les confessions religieuses.

Les considérations que l'on vient de faire ne suggèrent pourtant pas que ce soit la seule cause de la crise qui entraina un dépeuplement complet ou un échange des populations dans des villages de montagnes. Cependant, ces exceptions ne contestent pas la thèse présentée ${ }^{37}$, elle tient compte non seulement des observations détaillées sur l'histoire des villages en question. C'est déjà au XIIIe siècle que l'on commença la colonisation à caractère agricole des terrains montagneux en Petite-Pologne. Ce processus était fondé sur la population venant de l'extérieur: polonaise ou, parfois, allemande. On la continua pendant le siècle suivant ${ }^{38}$. Au XVe siècle et, en particulier, au XVIe siècle, une colonisation intensive des montagnes ne se basait pas sur les activités agricoles, mais sur une économie pastorale avancée qui fonctionnait selon les règles de ius Valachicum, ou bien, était un assemblage d'éléments du ius Valachicum et ceux du ius Theutonicum. Cela eut lieu dans la partie occidentale de la Petite-Pologne et les terres voisines du duché de Cieszyn. L'ampleur de cette expansion est confirmée par le fait que sur les terres de Boykos (actuellement dans les territoires de la Pologne et de l'Ukraine) presque $85 \%$ des villages furent fondés au XVIe siècle et au début du XVIIe siècle selon le ius Valachicum. Les $15 \%$ des villages furent fondés dans les siècles précédents ${ }^{39}$.

Il est plutôt indiscutable que ce furent des facteurs naturels qui forcèrent à cesser de fonder des villages agricoles plus rentables du point de vue des détenteurs des terres et à les substituer par ceux des bergers. En conséquence du Petit Âge Glaciaire, il n'existait plus d'alternative à la colonisation qui aurait été fondée au moins sur des éléments du ius Valachicum. Les sources fiscales de la deuxième moitié du XVIe siècle ont fourni, de manière inattendue, des informations qui confirmaient les difficultés auxquelles des bergers valaques devaient faire face, même s'ils connaissaient bien

${ }^{37}$ Une brève histoire du village Moczarne dans les Bieszczady (l'ancienne Terre de Sanok en Ruthénie de la Couronne) constitue un cas typique de ce genre de situations. Moczarne put être fondé vers la fin du XVIe siècle. En 1618, c'était un village presque complètement désert, car on n'y paya l'impôt que de 2 tan (dont l'un qui appartenait à un kniaź valaque). En plus, à Moczarne, il se trouvait alors $51 / 2$ tan et un moulin. En 1629, personne n'y habitait. À la lueur des déclarations des habitants de Solinka, un village valaque prochain, cet état des choses fut un effet d'une épidémie en 1622, les autres habitants furent tués par les Hongrois et les brigands (A. Fastnacht, Osadnictwo ziemi sanockiej w latach 1340-1650, [La colonisation de la Terre de Sanok dans les annés 1340-1650], Sanok 2007, s. 187-188.

38 Anna Rutkowska-Płachcińska, Sądeczyzna $w$ XIII $i$ XIV wieku, [La région de Sącz aux XIII et XIV siècles] Wrocław 1961, s. 67; M. Parczewski, Poczatki napływu ludności ruskiej na teren Karpat Zachodnich $w$ świetle archeologii [Le début de l'affluence de la population ruthène dans les Carpates Occidentales à la lueur des recherches archéologiques], „Archaeologia Historica”, 18: 1993, s. 93-97.

39 В.Ф.Інкін, Сільське суспільство Галицьького Прикарпаття у XVI - XVIII століттях: історичнінариси [La société rurale des Précarpates de Halicz depuis le XVIe au XVIII siècles: essais historiques], Львів 2004, s. 12-20; Fastnacht, Osadnictwo, s. 267. 
la réalité de la vie dans les montagnes. Les descriptions des bien royaux de la période de 1564 à 1565 et celle de l'an 1570 montrent l'état catastrophique du bétail et du cheptel ovin en particulier dans les villages analysés. C'était à cause de cela que les contribuables ne payèrent rien, ou bien, un mouton par 20 (vigesima), c'est-à-dire, ils acquittèrent un impôt minimal de ces animaux. Les habitants des villages en PetitePologne et en Ruthénie le justifiaient parfois par une maladie contagieuse qui décimait leurs troupeaux ${ }^{40}$. De temps en temps, on soulignait le caractère très répandu de l'épidémie, comme dans le cas du village Zinowińce (actuellement: Шевченка) situé dans le capitaneatus de Chmielnik, en Ruthénie de la Couronne: “il n'y avait pas de dîme sur les moutons, car ils furent morts comme dans d'autres villages" ${ }^{41}$. En même temps, les abeilles disparurent: "pourtant, les abeilles crevèrent. À côté du village, il y avait un rucher seigneurial, mais il fut détruit et il n'en resta rien. De même, ils durent payer un mouton par vingt, mais les animaux crevèrent aussi" ${ }^{42}$. Il faut noter que la chute de l'élevage de différents animaux eut lieu pendant une grave crise climatique qui se produisit au cours des années 60 et 70 du XVIe siècle ${ }^{43}$. Cela trouve sa confirmation dans le texte de la description des biens royaux de 1564 relatif à Przysietnica (le capitaneatus de Sącz). Ses habitants: "acquittent les contributions en moutons, qui a des moutons, paient 5 béliers sur 100 moutons. Maintenant, il n'y a que cinq paysans qui ont des moutons (...). Qui a des moutons, donne aussi 4 fromages, ils sont cinq aussi, car les moutons des autres crevèrent pendant des hivers rigoureux" ${ }^{\text {" }}$. Il est donc hors de doute qu'il existait une liaison entre cette épizootie et des phénomènes climatiques défavorables. Cela enrichit l'analyse des effets du Petit Âge Glaciaire sur les populations des Carpates.

${ }^{40}$ Par exemple, Жерела д оісториї Украӥни - Руси. vol. 7: Люстричи королівщин в руських землях корони з $p .1570$ [Sources pour l'étude de l'histoire de l'Ukraine - Ruthénie. La description des biens royaux en Ruthénie de 1570], wyd. Михаил Грушевский, (depuis: Грушевский, 1903), Львів 1903): s. 73,141, 156-158, 172, 193-194, 272-273, 286; Ориси королівщин в руськихземлях XVI віку [Les descriptions des biens royaux en Ruthénie au XVIe siècle], vol.1, wyd. М. Грушевский, Львів 1895, s. 8-9, 64, 66, 94; Архив Юго-Западной России, 7/2: Акты о заселеніиюго-западной Россіи [Archives de la Russie sud-ouest, 7.2: Documents concernant le peuplement de la Russie sud-ouest], Киев 1890, s. 150 151,173-174; Lustracja województw ruskiego, podolskiego i betskiego 1564-1565 [La Description des bien royaux dans les palatinati de Ruthénie, de Podolie et de Bełz], wyd. K. Chłapowski., H. Żytkowicz, vol. 1, Warszawa-Łódź 1992, s. 169, 230; Lustracja województw ruskiego, podolskiego i betskiego 15641565, wyd. K. Chłapowski, H. Żytkowicz, vol. 2, Warszawa 2001, s. 226.

${ }^{41}$ Грушевский 1903, s. 73.

${ }^{42}$ Le fragment cité concerne la situation en 1570, à Demów, un village valaque (actuellement: Дернів), situé dans la zone frontalière de la Terre de Lwów en ancienne Pologne et du palatinatus de Bełz (Грушевский 1903, s. 272-273).

${ }^{43}$ Dobrovolný et al., Monthly, s. 93.

${ }^{44}$ Lustracja, vol.1, s. 175. 
Comme les considérations prévues pour cette étude touchent à leur fin, il convient d'en tirer quelques conclusions plus générales. Des observations plus détaillées permettent d' avancer une thèse générale, selon laquelle le refroidissement du climat et l'intensification des catastrophes météorologiques pendant le Petit Âge Glaciaire furent la cause de profonds changements concernant l'aménagement de l'espace des montagnes et celui des zones sous montagneuses. Le ius Valachicum implanté par des éléments d'origine étrangère (y compris des Valaques ethniques) ou, au moins, reçu par la population locale était l'instrument qui rendait possibles ces changements. Cette métamorphose ne concernait pas seulement des aspects économiques et juridiques, mais aussi des ethniques, sociaux, et même, religieux. L'auteur de la présente étude est convaincu qu' élargir des recherches sur tout le territoire des Carpates devient urgent. Comme le PAG fut un phénomène global, il faut donc se douter que les communautés qui existaient dans toute cette région étaient soumises aux transformations analogiques à celles des Carpates Occidentales. Ces travaux devraient être entrepris par un groupe international de recherche qui réunirait non seulement des historiens, mais aussi des représentants des sciences de la terre et ceux des sciences naturelles. Aujourd'hui, il existe des conditions favorables pour développer ces initiatives.

\section{BIBLIOGRAFIA}

Baranowski Ignacy Tadeusz, U stóp Babiej Góry, „Przegląd Historyczny”, 20 : 1916, nr 1, s. 74-93.

Bębynek Władysław, Starostwo muszyńskie. Własność biskupów krakowskich, „Przewodnik Naukowy i Literacki. Dodatek do „Gazety Lwowskiej”, 42: 1914, nr 1, s. 11-22; 211-223.

Beňko Jan, Osidlenie severného Slovenska, Košice 1985.

Chaloupecký Václav, Valaši na Slovensku, Praha 1947.

Chmielewski Stefan, Gospodarka rolna i hodowlana w Polsce w XIV i XV w. Studia z dziejów gospodarstwa wiejskiego, vol. $5 \mathrm{nr}$ 2, red. J. Leskiewiczowa, Warszawa 1963, s. 1-158.

Czajkowski Jerzy, Studia nad Łemkowszczyzna, Sanok 1999.

Czajkowski Jerzy, Dzieje osadnictwa historycznego na Podkarpaciu i jego odzwierciedlenie w grupach etnicznych, w : Łemkowie w historii i kulturze Karpat, red. J. Czajkowski, vol. 1, Rzeszów 1995, s. $27-166$.

Długopolski Edmund, Przyczynki do osadnictwa wołoskiego w Karpatach. Sprawozdanie Filii c.k. Gimnazjum św. Jacka w Krakowie, Kraków 1916.

Dobrovolný Petr (et al.), Monthly, seasonal and annual temperature reconstructions for Central Europe derived from documentary evidence and instrumental records since AD 1500, "Climatic Change" 101: 2010, nr 1-2, s. 69-107.

Dobrowolska Maria, Procesy osadnicze w dorzeczu Wistoki i Białej Dunajcowej w tysiącleciu, Kraków 1985.

Dobrowolski Kazimierz, Zderzenie kultury rolniczej z pasterska, „Sprawozdania z Czynności i Posiedzeń PAU', 5: 1939, s. 191-194.

Fastnacht Adam, Osadnictwo ziemi sanockiej w latach 1340-1650, Sanok 2007. 
Fastnacht Adam, Słownik historyczno-geograficzny ziemi sanockiej w średniowieczu: vol. 3 (O-Ż), Kraków 2002.

Grove Jean M., The initiation of the „Little Ice Age” in regions round the North Atlantic, "Climatic Change" 48 : 2001, nr 1, 53-82.

Guzik Czesław, Zmiany użytkowania ziemi $i$ sposobów gospodarowania w rolnictwie Podhala, w : Geografia i Sacrum, vol.1, red. B. Domański, S. Skiba, Kraków 2005, s. 85-93.

Holzhauser Hanspeter, Magny Michel and Zumbuhl Heinz J., Glacier and lake-level variations in westcentral Europe over the last 3500 years, „The Holocene” $15: 2005$, nr 6, s. 789-801.

Инкін Васил Ф., Крестьянски йобщинный строй в галицком Прикарпатье. (Опыт сравнительного изучения поземельных союзов). Автореферат диссертации, Львов 1978.

Інкін Васил Ф., Сільське суспільство Галицького Прикарпаття у XVI - XVIII століттях: історичнінариси, Львів 2004.

Janeczek Andrzej, Osadnictwo pogranicza polsko-ruskiego. Województwo betskie od schytku XIV do poczatku XVII w., Wrocław 1991.

Jawor Grzegorz, Aşezările de drept valah şi locuitorii lor din Rutenia Roşie în Evul Mediu târziu, trad. Gabriela Gavril-Antonosei, Jaşi 2013.

Jawor Grzegorz, Northern Extent of Settlement on the Wallachian Law in Medieval Poland, "Res Historica» 41 : 2016, s. 35-49.

Jawor Grzegorz, Волоське осадництво на теренах Розточчя у пізньоту середньовіччі, „Вісник Львівського Үніверситету“. Серія історична 35/36: 2000, s. 58-75.

Jawor Grzegorz, Wspótistnienie grup etnicznych na Rusi Czerwonej w XV-XVI wieku na przyktadzie stosunku do społeczności wołoskich, „Annales UMCS“, sectio F. Historia, 52/53: 1997/1998, s. 5365.

Kobylińska Józefa, Językowy obraz wsi beskidzkiej w XVII wieku na przykladzie nazw ziemi i jej mieszkańców w Księgach gromadzkich wsi Kasina Wielka, „Język Polski”, 79: 1996, vol. 4-5, s. 337-348.

Kotarba Adam, Mała epoka lodowa w Tatrach Wysokich, w : VII Zjazd Geomorfologów Polskich. Wspótczesna ewolucja rzeźby Polski, red. A.Kotarba, K. Krzemień, J. Święchowicz, Kraków 2005, s. $50-65$.

Kotarba Adam, Zdarzenia geomorfologiczne w Tatrach Wysokich podczas małej epoki lodowej, w : Rola Małej Epoki Lodowej w przeksztatcaniu środowiska przyrodniczego Tatr, red. A. Kotarba, Warszawa 2004, s. 9-56.

Kuraś Stanisław, Osadnictwo i zagadnienia wiejskie w Gorlickiem do połowy XVI w., w: Nad rzeka Ropa. Vol. 3. Szkice historyczne, red. Z Żarnecka, Kraków 1968, s. 61-92.

Luterbacher Jürg (et al.), European Seasonal and Annual Temperature Variability, Trends, and Extremes Since 1500, „Science” 303 (5663): 2004, s. 1499-1503.

Macůrek Josef, Valaši v západnich Karpatech v 15-18. Stoletni, Ostrava, 1959.

Maruszczak Henyk, Tendencje sekularne i zjawiska ekstremalne $w$ rozwoju rzeźby małopolskich wyżyn lessowych w czasach historycznych, „Czasopismo Geograficzne” 57: 1986, nr 2, s. 271-288.

Maruszczak Henryk, Zmiany środowiska w okresie historycznym, w : Geografia Polski. Środowisko geograficzne, red. L. Starkel, Warszawa 1999, s. 182-205.

Matthews John A. and Briffa Keith R., "The „Little Ice Age”: Re-Evaluation of an Evolving Concept, „Geografiska Annaler”, 87: 2004, nr 1, s. 17-36.

Morawski Szczęsny, Sądecczyzna za Jagiellonów z miasty spiskiemi i księstwem oświęcimskim, vol. 2, Kraków 1865.

Niedźwiedź Tadeusz, Rekonstrukcja warunków termicznych lata w Tatrach od 1550 roku, w : Rola Matej Epoki Lodowej..., s. 57-88.

Panic Idzi, Śląsk Cieszyński w średniowieczu (do 1528 roku). Dzieje Śląska Cieszyńskiego od zarania do czasów wspótczesnych vol. 2, Cieszyn 2010.

Panic Idzi, Śląsk Cieszyński w początkach czasów nowożytnych (1528-1653). Dzieje Śląska Cieszyńskiego od zarania do czasów wspótczesnych, vol. 3, Cieszyn 2011. 
Parczewski Michał, Początki napływu ludności ruskiej na teren Karpat Zachodnich w świetle archeologii, „Archaeologia Historica”, 18: 1993, s. 93-97.

Perzanowski Zbigniew, Przegląd najstarszych dziejów osad wiejskich regionu krośnieńskiego (stownik geograficzno-historyczny), w : Krosno. Studia z dziejów miasta i regionu, vol. 2 (1918-1970), red. J. Garbacik, Krosno 1973, s. 385-418.

Pieradzka Krystyna, Na szlakach Łemkowszczyzny, Kraków 1939.

Popiołek Franciszek, Historia osadnictwa w Beskidzie Śląskim, Katowice 1939.

Prochaska Antoni, Jaśliska, miasteczko i klucz biskupów przemyskich, „Przewodnik Naukowy i Literacki.

Dodatek miesięczny do „Gazety Lwowskiej”, 17: 1889, nr 1, s. 57-77.

Putek Józef, Miłościwe pany i krnąbrne chłopy włościany, Warszawa 1959.

Rutkowska-Płachcińska Anna, Sadeczyzna w XIII i XIV wieku, Wrocław 1961.

Stadnicki Aleksander, O wsiach tak zwanych woloskich na pótnocnym stoku Karpat, Lwów 1848.

Szczotka Stanisław, Studia z dziejów prawa woloskiego w Polsce, "Czasopismo Prawno-Historyczne”, 2: 1948 , s. $355-416$.

Walawender Antoni, Kronika klęsk elementarnych Polsce i krajach sąsiednich w latach 1450-1586, Lwów 1932. 